\title{
Reconocimiento de la participación activa de la víctima en el proceso penal a la luz de los derechos humanos
}

\author{
Recognition of the active participation of the victim in the criminal \\ process in the light of human rights
}

\begin{abstract}
Roberto Omar Galiano
Resumen: Actualmente se han comenzado a repensar algunas nociones clásicas del derecho penal y procesal penal. Ciertos conceptos claves, han entrado en crisis. Uno de los principales temas de gran debate resulta ser la evolución hacia una mayor participación de la víctima en el proceso penal. Ello produjo que se generen determinados puntos de tensión o posibles colisiones entre las garantías constitucionales de los distintos sujetos involucrados. Por ello, en el desarrollo de este trabajo analizaremos la vinculación entre la participación de la víctima en el proceso penal y su eventual afectación a los derechos del imputado. Para ello, de un modo breve, haremos referencia a determinados aspectos nucleares de esta cuestión, y destacaremos pronunciamientos que estimamos relevantes emitidos por la Corte Interamericana de Derechos Humanos y el Tribunal Europeo de Derechos Humanos. Por último, expondremos nuestras conclusiones.
\end{abstract}

Palabras claves: Querellante. Autonomía. Acusaciones múltiples. Derechos de defensa.

\begin{abstract}
Currently, some classical notions of criminal and criminal procedural law have begun to be rethougth. Certain key concepts have entered into crisis. One of the main topics of great debate turns out to be the evolution towards a greater participation of the victim in the criminal process. This led to the generation of certain tension points or possible collisions between the constitutional guarantees of the different subjects involved. Therefore, in the development of this work we will analyze the link between the victim's participation in the criminal process and its eventual impact on the rights of the accused. To do this, in a briek way, we will make reference to certain nuclear aspects of this issue, and we will highlight pronouncements that we consider relevant issued by the InterAmerican Court of Human Rights and the European Court of Human Rights. Finally, we will present out conclusions.
\end{abstract}

Keywords: Complainant. Autonomy. Multiple accusations. Right of defense.

\footnotetext{
${ }^{1}$ Facultad de Derecho, Universidad Nacional de Rosario - Argentina. Abogado, Magister en Derecho Procesal por la Universidad Nacional de Rosario (Argentina). Magister en seguridad jurídica y justicia penal en iberoamérica por la Universidad de Salamanca (España). Ayudante Fiscal de la provincia de San Juan, Argentina. Actualmente trabajando en la Tesis de la carrera de Doctorado en Derecho. Asistencia a cursos de especialización en la ciudad de Rosario, Buenos Aires y Salamanca (España).
} 


\section{Introducción}

Conforme los lineamientos de la doctrina penal clásica, la potestad represiva del sistema penal se inicia con el instituto de la acción penal. En la mayoría de los casos, quien únicamente se encontraba habilitado a ejercitarla, era el Estado.

Este derecho-deber del Estado, lo habilitaba (eventualmente y luego de transitar un proceso penal) a aplicarle una pena establecida por ley previamente al partícipe de un hecho penalmente típico, antijurídico y culpable.

No obstante ello, con el pasar del tiempo, comenzaron a diferenciarse distintos tipos de acciones penales, en función a la entidad del bien jurídico protegido y otras cuestiones en juego, como por ejemplo, el pudor de la víctima. Así fue que surgió la clasificación de las acciones penales como: de carácter público, dependiente de instancia privada o, directamente, privada.

Conforme esta concepción tradicional, todo tipo de acción penal, lleva implícita la naturaleza jurídica de una acción "pública", puesto que aunque su ejercicio puede depender de la instancia de un particular ofendido por el delito o pertenecer a este, el derecho-deber que conlleva, implica la aplicación de una pena pública, tendiente a satisfacer el interés social en el castigo del delincuente (NUÑEZ, 1999).

Con el paso del tiempo, precisamente luego de la segunda Guerra Mundial, y con la celebración de los Tratados y Convenciones Internacionales, los cuales dan origen a las obligaciones de los Estados de tutelar "nuevos" derechos fundamentales de las personas que se encuentran dentro de sus territorios, se comenzó a generar un espacio en el que se contribuyó a repensar los principios que rigieron el proceso penal tradicional. 
Como una de las principales consecuencias de aquel proceso de cambio, podemos señalar la modificación que adoptaron varios países en cuanto al sistema procesal penal: habiendo pasado del sistema inquisitivo al, acusatorio y adversarial.

Este camino de transición habilitó a otros institutos (hasta ese momento, ubicados en un segundo plano) que tomaran mayor protagonismo. Tal es el caso de la víctima del delito. Este sujeto que ocupaba en el derecho penal clásico un rol netamente secundario, pasó a ubicarse en el centro de la escena. Nutrieron las discusiones jurídicas al respecto, nuevas disciplinas que abordaron estos aspectos, como por ejemplo lo fueron, la victimología (originada en 1948 por el Dr. Mendelshon) y la víctimo-dogmática (cuyo origen se remonta a la doctrina alemana). También lo hicieron los estudios de psicología social de 1970, que se referían a la insolidaridad y pasividad de la sociedad en relación a las víctimas del delito.

Es así que surge en los últimos años un nuevo paradigma en torno a la participación de la víctima en el proceso penal. Se advierte una significativa revalorización de aquel sujeto dentro del proceso. Aquel reconocimiento se funda -en muchas oportunidades- en la supremacía de los derechos humanos por sobre cualquier ordenamiento normativo; entendidos estos derechos, como garantías inalienables que todo ciudadano detenta, en este caso frente a la actividad punitiva del Estado, dirigida no contra sí -ya que es víctima-, sino contra un tercero presunto autor de un delito.

Así es como vamos a encontrar en el diseño del nuevo proceso penal a tres protagonistas: imputado, víctima y Estado. Cada uno de ellos, con sus propios intereses legítimos que deben ser conciliados para conseguir un sistema armónico de garantías. (DELGADO MARTÍN, 2004)

En relación a esto último, debemos también tener presente partimos de la noción de Estado Constitucional de Derecho, entendido este (en lo aquí pertinente) como la posibilidad que tienen los ciudadanos de acudir a los tribunales con el objeto de lograr la satisfacción de sus intereses y derechos, 
o al menos, que sean valorados por un juzgador imparcial, lo que en definitiva permitirá resolver un conflicto planteado en el plano de la realidad.

No parece exagerado afirmar que el modo en que un ordenamiento regula la titularidad y el ejercicio de la acción penal posee una innegable relevancia constitucional.

En cuanto al contenido de las legislaciones nacionales, en algunas ocasiones se la dota a la víctima de mayor participación, en otras incluso, se le otorga la autonomía como parte -actor penal, querellante- para llevar adelante el proceso por sí mismo, aun ante el posible desistimiento del Ministerio Público Fiscal para continuar instando la acción.

No obstante ello, y tal como ocurre en todo proceso paulatino de cambio, aún no existe uniformidad en la jurisprudencia sobre los alcances que corresponde otorgarle a este sujeto. Por ello, será parte de este Trabajo analizar el contenido de determinados pronunciamientos relevantes de distintos Tribunales regionales con competencia en Derechos Humanos con el objeto de valorar los argumentos que dichos Tribunales ponderan en casos donde estos aspectos se hayan encontrado en juego.

Uno de los puntos más críticos sobre estas cuestiones se presenta en la coexistencia que puede presentarse dentro de un mismo proceso de más de una acusación (la del Fiscal por un lado, y la del querellante autónomo por otra), o porque no, varias querellas dirigidas todas ellas contra un único sujeto, el imputado.

Ante este escenario, algunos autores se manifiestan en contra de aquella multiplicidad de acusaciones, señalando que ello implica una violación a la prohibición de la doble incriminación penal, como así también afecta el principio del contradictorio, el principio de congruencia y el de igualdad de armas.

Sobre esta línea de pensamiento cabe citar a modo de ejemplo, a Bernd SCHÜNEMANN (2002) quien sostiene que: "...la autonomía de la 
víctima, provoca una lesión del imperativo "balance" o equilibrio de posiciones que debe existir en el proceso penal en su conjunto, pues este reforzamiento de la posición de la víctima conlleva una carga adicional para el imputado."

Sin perjuicio de ello, en la vereda contraria se posicionan otros autores que se manifiestan a favor de aquella multiplicidad de acusaciones, indicando que ello, a su entender, no afecta las garantías constitucionales de la persona imputada, como así también que se funda en la primacía de la efectiva protección de los derechos de la víctima tales como: a ser oído, a la tutela judicial efectiva y al derecho de acceso a la jurisdicción.

Será materia de este trabajo entonces, abordar esta situación, analizar pronunciamientos emitidos por Tribunales supranacionales, destacando los casos de la Corte Interamericana de DDHH y el Tribunal Europeo de DDHH, en los que se analicen aristas de estos institutos y su interacción en un mismo proceso penal, a fin de determinar si de alguna manera, esta multiplicidad de acusaciones podría afectar los derechos del imputado.

\section{Eficacia de resoluciones emitidas por tribunales internacionales}

La Corte Interamericana de Derecho Humanos dictó su primer pronunciamiento el día 29 de julio de 1988. En aquella oportunidad condenó al Estado de Honduras por haber cometido violaciones a los derechos humanos, concretamente, en relación al secuestro de Rodríguez Velázquez en la ciudad de Tegucigalpa (Honduras) en el año 1981, acto que fue llevado a cabo por un grupo parapolicia, provocando así la desaparición de su persona. La Corte entendió que se habían violado derechos tales como el derecho de los familiares de Rodríguez Velázquez a obtener por parte del Estado una respuesta sólida y cuya investigación sea responsable, como así 
también la violación a los deberes de respeto y garantía del derecho a la integridad personal (artículo 5 del Pacto de San José de Costa Rica).

Si pensamos en la tutela de los Derechos Humanos en el plano supranacional, podemos indicar que este nuevo concepto viene a romper el modelo clásico de poder absoluto del soberano. Marca un claro límite al poder. El propio ciudadano es ahora quien toma protagonismo como defensor de aquellos derechos frente al avasallamiento del poder. Se lo legitima en el plano internacional como sujeto del derecho internacional, vale decir, se lo faculta a dirigirse a la Comisión Interamericana de Derechos Humanos con el objeto de que este organismo investigue la presunta violación a aquellos derechos y en su caso, presente el caso ante la Corte Interamericana de Derechos Humanos.

Con el paso del tiempo, aquellos pronunciamientos emitidos comenzaron a generar lo que se conoce como "la doctrina legal de tribunales internacionales", la cual se establece como una importante fuente de interpretación de tanto o más valor que los propios tratados. Puesto que son justamente estos pronunciamientos los que definen el alcance o extensión de la normativa internacional. Por ello mismo es que, el contenido del Pacto de San José de Costa Rica - sin perjuicio de otros que al día de la fecha se encuentran vigentes también-, resulta tener directa operatividad en el plano interno -vale decir, distando notoriamente del alcance que podría tener una norma con carácter meramente programática, como podría ser una Declaración de derechos (y sin que ello implique restarle de ningún modo la importancia que tienen como parte esencial en la evolución del Derecho internacional público)-.

Ante ello, en caso de producirse violación a alguna norma regulada, la misma Convención con la finalidad de evitar la impunidad de tales actos ilícitos, creó órganos destinados a velar por el cumplimiento de aquellas; órganos que a su vez, se encuentran facultados a imponer sanciones a los Estados partes. 
Por nuestra parte, la Corte Suprema de Justicia de la Nación de Argentina nos ha señalado en pronunciamientos tales como "Bramajo" que los tratados que forman parte del bloque de constitucionalidad se aplican de modo operativo "en las condiciones de su vigencia", haciendo referencia con ello al alcance dado por los pronunciamientos emitidos, entre otros, por la Corte Interamericana de Derechos humanos. En tal sentido se ha sostenido que no se puede conocer en profundidad un sistema de protección de los derechos humanos, si no se saben las líneas viscerales del órgano decisor.

Así a modo de ejemplo cabe señalar, en cuanto a la participación de la víctima en el proceso penal, que la Comisión Interamericana de Derechos humanos indicó que: "en buena parte de los sistemas penales de América Latina existe el derecho de la víctima o su representante a querellar en el juicio penal, en consecuencia, el acceso a la jurisdicción por parte de la víctima de un delito en los sistemas que lo autorizan, como el argentino, deviene un derecho fundamental del ciudadano."

Resulta importante entonces tener presente entonces que, el derecho internacional de los derechos humanos atraviesa sustancialmente todo derecho positivo nacional. Por lo tanto, no aplicar aquellas disposiciones internacionales, implica no aplicar el derecho vigente.

Luigi Ferrajoli, utilizando una expresión de Ronald Dworkin, señala que es necesario tomar en serio el derecho internacional y por lo tanto, aceptar que sus principios son vinculantes y que su diseño normativo ofrece una alternativa frente a lo que de hecho ocurre; hacerlos valer como claves de interpretación y como fuentes de crítica y de deslegitimación de lo existente.

3. Evolución Jurisprudencial de la Corte Interamericana de Derechos Humanos 
Tal como adelantáramos, los pronunciamientos de los tribunales internacionales de derechos humanos son los que definen el alcance o extensión de la normativa internacional.

Veamos a continuación el contenido de algunos fallos seleccionados en los que se trató la participación de la víctima en el proceso penal, haciendo hincapié -en este análisis- en intentar destacar las facultades reconocidas o denegadas a este sujeto dentro del proceso.

En tal sentido, en fecha 2/02/2001 la Corte Interamericana de Derechos Humanos emitió el fallo “Baena, Ricardo y otros c/ Panamá”, en el cual se reconoce la jerarquía constitucional de los tratados de derechos humanos. En esta oportunidad la Comisión Interamericana de Derechos Humanos sometió ante la Corte una demanda contra la República de Panamá para decidir sobre la violación a la Convención Americana de Derechos Humanos en los actos de aquél que derivaron en la destitución de doscientos setenta empleados públicos participantes en una huelga por reclamos salariales, a quienes se acusó de complicidad con un movimiento militar. El Estado alegó la grave situación de emergencia que amenazaba la seguridad nacional. La Corte declaró la existencia de infracción, entre otros, al debido proceso y al derecho de asociación. Sostuvo que Panamá incumplió la obligación de respetar, hacer respetar y garantizar los derechos de las víctimas de este caso. Además del incumplimiento de las garantías judiciales, las autoridades jurisdiccionales declararon que no podía aplicarse la norma convencional interamericana porque carecía de jerarquía constitucional, colocando los tratados internacionales de derechos humanos en un nivel de segunda categoría.

Respecto de nuestro país Argentina, podemos citar el fallo "Bulacio c/ Argentina” dictado en fecha 18/09/2003, cuya relevancia -para nuestro análisis- recae en la decisión adoptada por la Corte Interamericana en relación a la participación de la víctima dentro del proceso penal, el acceso a 
la jurisdicción y plena capacidad de actuar en todas las instancias, ello a la luz de la Convención Americana.

En tal sentido la Corte sostuvo que todo Estado parte de la Convención Americana tiene el deber de investigar las violaciones de los derechos humanos y sancionar a los autores, como así también a los que encubran dichas violaciones. Respecto de las personas que se consideren víctimas de éstas o bien sus familiares tienen derecho de acceder a la justicia para conseguir que se cumpla, en su beneficio y en el del conjunto de la sociedad, ese deber del Estado.

Por todo ello es necesario que el Estado prosiga y concluya la investigación del conjunto de los hechos y sancione a los responsables de los mismos. Los familiares de la víctima deberán tener pleno acceso y capacidad de actuar en todas las etapas e instancias de dichas investigaciones, de acuerdo con la ley interna y las normas de la Convención Americana.

La Corte ha señalado en otras oportunidades anteriores que este deber impone a los Estados Partes la obligación general de adecuar su derecho interno a las normas de la propia Convención, para garantizar así los derechos consagrados en ésta. Las disposiciones de derecho interno que sirvan a este fin han de ser efectivas, lo que significa que el Estado debe adoptar todas las medidas necesarias para que lo establecido en la Convención sea realmente cumplido.

Casi un año luego de este pronunciamiento, el día 2/07/2004, se emitió la sentencia en el caso "Herrera Ulloa, Mauricio c. Costa Rica". Su relevancia está dada por reconocer que la vigencia de los derechos de las víctimas se encuentra íntimamente vinculada con la defensa permanente por el acceso a la justicia.

En tal sentido, La Corte Interamericana de Derechos Humanos declaró que Costa Rica había incurrido en violación a los derechos a la libertad de pensamiento y expresión e imparcialidad de los jueces, debido a la condena penal impuesta al periodista y al editor que se habían limitado a 
reproducir parcialmente información que daba cuenta de que un diplomático costarricense había incurrido en ciertas conductas ilícitas.

Sostuvo que difícilmente se podría desempeñar la tutela internacional de los derechos humanos si no se contara con la frecuente y eficiente concurrencia de profesionales que sustentan, tanto en el orden interno como en el internacional, los derechos de la víctima. Aquéllos constituyen una pieza importante -y a menudo decisiva- para el conjunto de actividades destinadas a favorecer el acceso a la justicia.

Otro fallo que cabe mencionar en el presente recorrido es el caso “Comunidad Indígena Yakye Axa c. Paraguay” dictado el día 17/06/2005. Su importancia está dada porque se expresa en relación a la interpretación evolutiva del derecho internacional de los derechos humanos, esta incluye el reconocimiento de la ampliación del concepto de víctima.

La Comisión Interamericana de Derechos Humanos promovió demanda contra el Estado del Paraguay, con motivo de una denuncia presentada por organizaciones no gubernamentales, en cuanto no habría garantizado el derecho de propiedad ancestral de la Comunidad indígena Yakye Axa, ya que desde 1993 se encontraría en tramitación la solicitud de reivindicación territorial, sin que se haya resuelto satisfactoriamente, manteniéndola en un estado de vulnerabilidad alimenticia, médica y sanitaria, que amenaza en forma continua la supervivencia de sus miembros así como su integridad. El Tribunal dispuso, entre otras medidas, que el Estado demandado debía entregar a los miembros de la comunidad su territorio tradicional de manera gratuita en un plazo máximo de tres años.

La Corte consideró que con fallos como el presente se contribuye a la interpretación evolutiva del derecho internacional de los derechos humanos; particularmente sobre el reconocimiento al derecho al proyecto de vida, la ampliación del concepto de víctima, la incorporación de ésta al proceso contencioso a través de las reformas reglamentarias, el derecho a la asistencia consular de la persona detenida policial o judicialmente, como 
parte de la garantía del debido proceso, el reconocimiento de los derechos laborales de los migrantes indocumentados.

Luego de este, vino la sentencia del caso "Almonacid, Arellano y otros c. Chile”, el día 26/09/2006. En el mismo se estableció que las leyes de autoamnistía conducen a la indefensión de las víctimas y a la perpetuación de la impunidad, por lo que son manifiestamente incompatibles con el espíritu de la Convención Americana. Con ellas, se obstaculiza la investigación y el acceso a la justicia. Por otra parte, sostuvo que es un deber del Estado el asegurar que las víctimas tengan pleno acceso y capacidad de actuar en todas las etapas e instancias de dichas investigaciones, de acuerdo con la ley interna y las normas de la Convención Americana, dado que este es el interés principal de ellas. Aquellas leyes dejan a los victimados y sus familiares en la más completa e inadmisible indefensión.

La cuestión versó sobre la "dictadura militar" en Chile, "dentro de una política de Estado encaminada a causar miedo, atacó masiva y sistemáticamente a sectores de la población civil considerados como opositora al régimen, mediante una serie de graves violaciones de los derechos humanos y del derecho internacional, entre las cuales se cuentan al menos 3.197 víctimas de ejecuciones sumarias y desapariciones forzadas, y 33.221 detenidos, de quienes una inmensa mayoría fue víctima de tortura". Entre estas numerosas víctimas estuvo el Sr. Almonacid Arellano, ejecutado extrajudicialmente por agentes estatales, en medio a un "patrón sistemático y generalizado" de crímenes contra la población civil.

En el desarrollo de los argumentos sostenidos por el Tribunal se sostuvo que el Estado debe asegurar que la señora Elvira del Rosario Gómez Olivares y los señores Alfredo, Alexis y José Luis Almonacid Gómez tengan pleno acceso y capacidad de actuar en todas las etapas e instancias de dichas investigaciones, de acuerdo con la ley interna y las normas de la Convención Americana. 
Otro caso fue "Bueno Alves c. Argentina” de fecha 11/05/2007. En este, el Estado Argentino reconoció su responsabilidad internacional por la violación de los derechos y garantías judiciales. Es un deber del Estado asegurar que la víctima tenga pleno acceso y capacidad de actuar en todas las etapas e instancias de las investigaciones y procesos, de acuerdo con la ley interna y las normas de la Convención Americana -tomando como antecedente el pronunciamiento efectuado en el caso "Almonacid, Arellano y otros c. Chile".

La cuestión giraba en torno a la pérdida parcial sufrida por una persona extranjera de su audición y severos daños psicológicos, producto de la tortura de la que fue objeto al ser detenido en sede policial. Ante la culminación del proceso judicial sin que se hubiese identificado y sancionado a los responsables del ilícito, la víctima y sus familiares denunciaron a la República Argentina ante la Comisión Interamericana de Derechos Humanos. El Estado Argentino reconoció su responsabilidad internacional por los hechos y la violación de los derechos a la integridad personal, garantías judiciales y protección judicial. La Corte Interamericana aceptó el reconocimiento efectuado por el Estado y lo condenó a indemnizar a las víctimas por los daños materiales e inmateriales.

Esta Corte ha afirmado en otras oportunidades, -y en relación al alcance del concepto de víctima- que los familiares de las víctimas directas de violaciones de los derechos humanos pueden ser, a su vez, víctimas ellas mismas. Entre los extremos a considerar se encuentran la existencia de un estrecho vínculo familiar, las circunstancias particulares de la relación con la víctima, la forma en que el familiar fue testigo de los eventos violatorios y se involucró en la búsqueda de justicia y la respuesta ofrecida por el Estado a las gestiones realizadas.

Tras ello se dictó otra condena contra el Estado Argentino, en el "Caso Bayarri vs. Argentina”, cuya sentencia fue emitida el día 30 de octubre de 2008. En este pronunciamiento se dio la entidad de derecho humano a la 
tutela judicial efectiva. También reconoció el derecho de la víctima a constituirse en parte querellante y a obtener de los tribunales una respuesta en un tiempo prudencial, evitando generar dilaciones ante el paso excesivo del tiempo, y/o entorpecimientos indebidos que conduzcan a la impunidad, frustrando así la debida protección judicial de los derechos humanos.

La Corte considera que con motivo de la falta de una resolución pronta y definitiva de la denuncia penal presentada en este caso por hechos de tortura y privación ilegal de la libertad se afectó el derecho de la víctima a la debida protección judicial. Este derecho comprende no sólo el acceso del ofendido a los procesos penales en condiciones de querellante (énfasis propio), sino el derecho a obtener un pronunciamiento definitivo mediante mecanismos efectivos de justicia. Asimismo, tomando en cuenta tanto el notorio retardo en la investigación y en el proceso referido, sin que exista explicación razonada, como el reconocimiento de hechos formulado por el Estado, la Corte estima que Argentina violó los artículos 8.1 y 25.1 de la Convención Americana en perjuicio del señor Juan Carlos Bayarri.

Antes de continuar con el próximo pronunciamiento judicial, cabe que nos detengamos unos instantes, para destacar que del análisis que venimos realizando hasta este momento, entendemos que todo derecho humano dada su calidad de derecho fundamental- merece por parte del Derecho, una protección especial. Ante ello, y para que dicho "respeto" sea materialmente posible es necesario poner en marcha a la par de tal reconocimiento y declaración, el funcionamiento eficaz de herramientas, instrumentos cuyo objeto sea precisamente el ser un medio garantizador al cual los ciudadanos puedan acudir en caso que los mecanismos de efectivización provistos por el Estado resulten deficientes, y en su consecuencia, fallen.

Continuando con los fallos de la Corte Interamericana de Derechos Humanos, agregamos la sentencia del caso "Mohamed c. Argentina" de fecha 23/11/2012. Se estableció que bajo los artículos nº 8 y 25 de la Convención 
Americana, los Estados están obligados a suministrar recursos judiciales efectivos a las víctimas de violaciones de derechos humanos.

La cuestión versó sobre un accidente de tránsito en el cual un colectivero atropelló a un peatón. En primera instancia, el imputado fue absuelto. Apelada la decisión por el Ministerio Público Fiscal, aunque sin presentar agravios que sustentaran el recurso, el fallo fue revocado por la Cámara de Apelaciones, concluyendo en una condena por homicidio culposo. La defensa interpuso recurso extraordinario federal, el que fue denegado y dio lugar a la queja. La Corte Suprema de Justicia de la Nación desestimó el remedio federal aplicando el art. 280 del Cód. Procesal. La Corte Interamericana de Derechos Humanos, condenó a Argentina por la violación del art. 8.2 de la Convención Americana sobre Derechos Humanos.

Por último, en el caso "Gutiérrez y familia c. Argentina", la Corte Interamericana de Derechos Humanos dictó sentencia de fondo en fecha 25/11/2013. El caso se relaciona con el asesinato del subcomisario Gutiérrez el 29 de agosto de 1994, quien se encontraba investigando un caso de corrupción posteriormente conocido como [el] 'caso de la aduana paralela'[,] en el que se encontraban involucrados importantes empresarios y funcionarios gubernamentales de alta jerarquía. Por los hechos se abrió una investigación penal, la cual adoleció de "deficiencias fundamentales". No obstante ello, el Estado no adoptó las medidas necesarias para aclarar los hechos y las correspondientes responsabilidades. Luego de 17 años de los hechos, aún no se tenía certeza de las circunstancias de su muerte ni se ha sancionado a persona alguna por los hechos.

En tal sentido cabe destacar, en lo aquí pertinente, que la Corte destaca la obligación de investigar e identificar, juzgar y, en su caso, sancionar a los responsables de los hechos relacionados con la ejecución de Jorge Omar Gutiérrez, resaltando que los familiares del señor Gutiérrez sufrieron una afectación a sus derechos de acceso a la justicia, de verdad y de reparación, en razón de la actuación del Estado, se dispone que el Estado 
debe: a) remover todos los obstáculos de facto y de jure que impidan la debida investigación de los hechos en los respectivos procesos; b) asegurar que los distintos órganos del sistema de justicia involucrados en el caso cuenten con los recursos humanos y materiales necesarios para desempeñar sus tareas de manera adecuada; c) asegurar el pleno acceso y capacidad de actuar de los familiares del Subcomisario Jorge Omar Gutiérrez en todas las etapas de esta investigación, de acuerdo con la ley interna y las normas de la Convención Americana.

En síntesis, respecto de los fallos de la Corte Interamericana de Derechos Humanos, observamos que los hechos que subyacen en el fondo de las cuestiones versan -en la mayoría de los casos- sobre: lesiones seguidas de muertes sufridas por personas privadas de su libertad en unidades penitenciarias, y muertes durante dictaduras militares (plan sistemático).

Esto resulta útil destacar, toda vez que entendemos que tales situaciones conflictivas -como otras que en estos fallos no aparecenresultan ser situaciones de suma tensión entre diferentes bienes jurídicos. En lo que hace a nuestro tema, los debates en general se presentan sobre la base argumentativa en relación a la vulneración de los derechos reconocidos a la víctima establecidos en la Convención Americana.

Un segundo planteo importante de analizar es si la Corte en sus pronunciamientos emite posición alguna sobre el rol de la víctima dentro de una causa en la cual se investiga la presunta comisión de un ilícito de acción pública, vale decir, efectuando alguna crítica o no al trato que se le dio en el país en forma interna.

En relación al primer interrogante, destacamos que resulta ser uno de los objetivos principales de la Corte a lo largo de toda la cronología pronunciarse sobre la violación a los derechos de las víctimas de un delito. En tal sentido, de los lineamientos pronunciados por ella en los fallos "Baena, Ricardo y otros." (2001), "Herrera Ulloa, Mauricio c. Costa Rica" (2004), y "Comunidad Indígena Yakye Axa c. Paraguay" (2005) se reconoce 
la jerarquía constitucional de los Tratados de Derechos Humanos, como así también se opta por una interpretación evolutiva del derecho internacional de los derechos humanos, en la cual se incluye el reconocimiento de la ampliación del concepto de víctima.

En relación a la segunda cuestión, la Corte ha entendido que forma parte de sus derechos la participación activa en el proceso. A modo de ejemplo, en el Caso "Bulacio c/ Argentina" (2003) se ha defendido el acceso a la jurisdicción y la plena capacidad de actuar en todas las instancias, ello a la luz de la Convención americana; en el caso "Almonacid, Arellano y otros c. Chile” (2006) se sostuvo que las leyes de autoamnistía conducen a la indefensión de las víctimas y a la perpetuación de la impunidad. Se obstaculiza el acceso a la justicia. Es un deber del Estado el asegurar que las víctimas tengan pleno acceso y capacidad de actuar en todas las etapas e instancias de dichas investigaciones, de acuerdo con la ley interna y las normas de la Convención Americana, dado que este es el interés principal de ellas; finalmente en el Caso "Bayarri vs. Argentina" (2008) reconoció el derecho de la víctima a constituirse en parte querellante y a obtener de los tribunales una respuesta en un tiempo prudencial.

\section{Conclusiones. Nuestra postura y sus fundamentos}

Con el objeto de comenzar a delinear nuestras conclusiones, inicialmente retomaremos el primer fallo dictado por la Corte Interamericana de Derechos Humanos: el pronunciamiento dictado en día 29 de julio de 1988, oportunidad en la que condenó al Estado de Honduras por haber cometido violaciones a los derechos humanos, concretamente, en relación al secuestro de Rodríguez Velázquez en la ciudad de Tegucigalpa (Honduras) en el año 1981.

En dicho Fallo señaló el voto mayoritario que el denunciante no es parte, no obstante, el Dr. Piza en disidencia señaló que aquel sujeto (en el 
caso los familiares del desaparecido Velázquez Rodríguez) deben intervenir en la conversación sobre la fijación de la cuantía de la reparación. Ello, dado que el mismo goza de la calidad de parte material en el proceso... el denunciante, como parte activa y titular de los derecho reclamados, y por ende acreedor... lo único que la Convención veda al ser humano es la iniciativa de la acción (art. 61.1)... En consecuencia, no es dable derivar de esa limitación la conclusión de que también le está vedado al ser humano su condición autónoma de parte en el proceso una vez que este se haya iniciado...". Agrega que ello: "surge de una telesis finalista y abarcadora del sistema de protección internacional de los derechos humanos, sobre la base de una interpretación humanitaria de esta problemática, a la que ha llegado la Corte de Estramburgo, para asuntos similares." “...dijo la Corte Europea... en el caso Los Vagabundos, ese órgano judicial autorizó a los abogados de la víctima a incorporarse al pleito, con amplias facultades de intervenir en el mismo... en 1982 dicho cuerpo modificó su reglamento, permitiendo al denunciante, participar activamente en el proceso, salvo la posibilidad de llevar el tema al tribunal... el art. 44 de la convención europea, que como el 61.1 de la nuestra, veda al particular la posibilidad de introducir el asunto ante el órgano jurisdiccional del sistema."

También podemos tomar como disparador lo señalado en el Digesto de Jurisprudencia Latinoamericana sobre Derechos de las Víctimas ${ }^{2}$ (2014), en el que se destaca como un gran desafío en la actualidad poder establecer un adecuado balance entre los derechos de las víctimas de violaciones de derechos humanos y los derechos de los imputados responsables de aquellas conductas.

En tal sentido debemos señalar en primer lugar que la única opción concebible y aceptable, a nuestro humilde entender, es lograr que un derecho no se sacrifique con el fin de preservar el otro. Ello representan

\footnotetext{
${ }^{2}$ Elaborado por la Fundación para el Debido Proceso con sede en Washington, Estados Unidos durante el año 2014.
} 
múltiples esfuerzos en pos de obtener un debido equilibrio entre los derechos del imputados y los de la víctima.

No obstante, observamos que este, no resulta ser un tema de fácil tratamiento, dado que ha transcurrido numerosos años desde el dictado de los pronunciamientos mencionados, no obstante lo cual, el debate sigue plenamente vigente en la actualidad, con notable convicción de los representantes de cada postura al respecto.

Sobre las dos posturas (a favor o en contra), es posible advertir que los argumentos sostenidos por los autores que defienden la autonomía del querellante dentro del proceso penal, cuentan con el rasgo en común de sostener la primacía de los derechos humanos, por encima del ordenamiento jurídico nacional vigente ${ }^{3}$. Es decir se analizan aspectos que exceden de la normativa interna, recurriendo a elementos jurídicos pertenecientes al plano internacional. Para ello observamos que se toman tanto fragmentos de Convenciones de Derechos Humanos ratificadas por nuestro país que forman parte del bloque de constitucionalidad (a partir de la vigencia del art. 75 inc. 22 de la Constitución Nacional de Argentina) como así también a fallos pronunciados por la Corte Interamericana de Derechos Humanos.

En tal sentido los derechos que se reconocen como fundamentales $-\mathrm{y}$ sobre los cuales se basan los argumentos de este sector de la doctrina- son: la titularidad del bien jurídico protegido por el delito en cabeza de la víctima, el derecho de acceso a la justicia, el derecho a ser oído, el derecho de defensa de la propia víctima, y la tutela judicial efectiva ${ }^{4}$.

En efecto, se ha entendido que la pretensión surge de la titularidad del bien jurídico individual o de la afectación directa del bien jurídico protegido por una determinada norma de naturaleza penal. Por ello, quien puede pretender, puede accionar, caso contrario se niega acceso a la jurisdicción. A favor de esta interpretación, se encuentra el Dr. Adolfo

${ }^{3}$ Tal como sostiene MAIER, 1992.

${ }^{4}$ A modo de ejemplo podemos citar los autores FRANCESCHETTI; GAMBA, 2010, como así también BELFORTE; ZENERE, 2005, entre otros. 
Alvarado Velloso (FRANCESCHETTI; GAMBA, 2010). (nota: en entrevista con los autores de esta obra, fundamentó que desde la teoría general del proceso la legitimación de la victima para querellar en causas penales y la inconstitucionalidad del art. 71 del Código Penal).

Es así en este orden de ideas que, la participación de este sujeto, configura una faceta más de la participación de los sectores ciudadanos en la “cosa pública”. Por todo ello, consideramos que toda normativa que impida a la víctima la constitución de parte autónoma dentro de un proceso penal, atenta contra la teoría general del proceso, como así también resulta inconstitucional, de conformidad con los argumentos antes expuestos.

Así es como con la mayor participación de la víctima se advierte que el sistema penal adquiere mayor transparencia (ya que funciona "frente a los ojos" de los involucrados directos, y no a sus espaldas, como lo hizo durante muchos siglos). Además, estimo que ello contribuye a consolidar la imagen de las instituciones públicas democráticas frente a la sociedad en su conjunto, y en definitiva, a aumentar el grado de confianza que los ciudadanos tengan en las resoluciones emitidas por los órganos judiciales.

Actualmente vemos que en algunas legislaciones han habido recientemente avances notables en la materia, tales como sucedió en Argentina al sancionar el Congreso de la Nación la Ley de derechos y garantías de las personas víctimas de delitos (Ley 27.372), dentro de la cual se establece de modo novedoso, la creación del instituto del Defensor Público de víctimas en la órbita del Ministerio Público de la Defensa de la Nación, quien asiste a las víctimas de delitos en la órbita de delitos de competencia federal, tal como podrían ser las víctimas de delitos como la trata de personas, secuestro extorsivo, entre otros delitos.

Ahora bien, si trazamos en esta oportunidad un paralelismo con la situación en el derecho europeo comunitario, encontramos que la jurisprudencia europea supranacional de Derechos Humanos se encuentra trabajando precisamente durante los últimos años, en este mismo sentido, 
es decir, en el fortalecimiento del reconocimiento de los derechos de las víctimas, como así también su participación en el proceso penal.

Esto principalmente se evidencia en sentencias del Tribunal Europeo de Derechos Humanos (TEDH) sobre casos vinculados a temáticas de acceso a un recurso judicial efectivo, protección de las víctimas de violencia de género, casos de malos tratos por parte de la policía que no fueron debidamente investigados por las autoridades judiciales (violencia institucional), y aquellos donde la cuestión controvertida se presenta ante aspectos de regímenes migraciones de las legislaciones nacionales.

$\mathrm{Al}$ respecto resulta útil resaltar, por ejemplo, el pronunciamiento de aquel Tribunal en el caso N.D. y N.T. C/ ESPAÑA del mes de Octubre del año 2017 (vinculado a un caso contra España sobre una decisión migratoria), en el que se destacó que el artículo 13 del Convenio garantiza la existencia en Derecho interno de un recurso que permita alegar los derechos y libertades del Convenio tal como están consagrados en el mismo, que permita examinar el contenido de una "queja sostenible" y "efectiva".

Retomo la idea que mencioné relativa a la participación de aquellos sujetos directamente afectados por el conflicto penal, para señalar que además su intervención permite consolidar aspectos propios de la Justicia Restaurativa, generando espacios de consenso y en los que es posible lograr resultados de justicia material, es decir, donde intervengan los sujetos directamente afectados por el delito en la construcción de una solución. Según la propia Corte Suprema de Justicia de los Estados Unidos, estos mecanismos de Justicia penal negociada traen beneficios mutuos para todos los involucrados; los operadores judiciales, la víctima, el acusado e incluso al propio Estado. Todo esto contribuye a "humanizar" de alguna manera al proceso penal actual.

En resumen, si bien el Convenio Europeo de Derechos Humanos no señala el reconocimiento de la víctima de un delito de un modo expreso, su tutela y protección surgen claramente de los pronunciamientos del TEDH al 
realizar una interpretación armónica de aquel Instrumento, tal como por ejemplo ocurre, al referirse sobre los alcances del art. 6 sobre el derecho a un proceso equitativo.

Así es como el mencionado Tribunal refiere que ante posibles situaciones en las que las víctimas podrían, por ejemplo, sufrir actos en los cuales serían sometidas a una eventual revictimización, las mismas deben ser protegidas, evitando que sean expuestas a aquellos actos. Para ello, y con el fin de balancear estos derechos con el derecho de defensa de la persona imputada (quien cuenta con la facultad de poder controlar la prueba de cargo, es decir, la prueba que va a fundar la acusación que se formule en su contra) el Tribunal, en un caso concreto, ponderó que la defensa contó con la posibilidad de presenciar la audiencia en la que se recibió testimonio de la víctima en la etapa de instrucción o investigación, y que omitió acudir a la misma en forma voluntaria, por lo cual en ese caso particular, su derecho de defensa no se encontraba afectado (caso GAÑI C/ ESPAÑA del año 2013).

Por ello, considero que es tarea de todos nosotros, los operadores judiciales y académicos abocarnos a procurar mantener ese debido equilibrio entre los derechos fundamentales del imputado y los que le son propios a la víctima, ambos, esenciales en un Estado Constitucional de Derecho.

Sin dudas este, es uno de los grandes desafíos que se presentan en la actualidad, en gran parte de los sistemas procesales penales nacionales. No obstante, estoy convencido que nos encontramos, en conjunto como comunidad científica, en condiciones de enfrentarlo con seriedad y compromiso.

Por último, y dando cierre a este trabajo, compartimos el concepto de derecho humano formulado por el autor Luigi Ferrajoli. En tal sentido el mismo indica que son: los derechos que pertenecen a todas las personas naturales simplemente en cuanto tales, son los derechos primarios de las 
personas, se trata de los únicos derechos universales en el sentido sustancial (FERRAJOLI, 2011, p. 696-701).

\section{Bibliografia}

BELFORTE, Eduardo Ariel; ZENERE, Gisela Guillermina: "Acceso de la víctima al procedimiento penal como forma de garantizar su derecho a una investigación eficaz.". XXIII Congreso Nacional de Derecho Procesal (2005), Comisión : III) Procesal Penal, Subcomisión: 1: La crisis de eficacia de la investigación penal: causas, peligros, soluciones. Derecho de la víctima a una investigación eficaz, www.academiadederecho.org

DELGADO MARTIN, Joaquín, (2004) El estatuto de la víctima en el proceso penal español. fuente: https://dialnet.unirioja.es/. Estudios de derecho judicial, ISSN 1137-3520, $\mathrm{N}^{\circ} .58$ (Ejemplar dedicado a: Las reformas procesales), págs. 335-410.

FERRAJOLI, Luigi (2011), Principia Iuris, Madrid, España, Editorial Trotta, t. I, p. 696701.

FRANCESCHETTI, Gustavo; GAMBA, Silvia, 2010, El Querellante. La Reivindicación de la víctima en el proceso penal, Editorial Nova tesis, Rosario.

MAIER, Julio B. J, 1992, La Víctima y el sistema penal, incluido en el volumen De los delitos y de las víctimas, Editorial Ad-hoc, Buenos Aires.

NUÑEZ, Ricardo C. (1999), Manual de Derecho Penal. Parte General. 4Ta edición actualizada. Editora Marcos Lerner, Córdoba, Argentina.

SCHÜNEMANN, Bernd. (2002) Sistema del derecho penal y victimodogmática, en aa. vv. José Luís Diez Ripolles, Carlos María Romeo Casabona, Luís Gracia Martín y Juan Felipe Higuera Guimerá (eds.). La ciencia del Derecho penal ante el nuevo siglo. Libro homenaje al Profesor Doctor Don José Cerezo Mir, Madrid, España.

Artigo recebido em: 22/10/2019.

Aceito para publicação em: 10/08/2021. 